\title{
SOME IMPROPER INTEGRALS INVOLVING THE SQUARE OF THE TAIL OF THE SINE AND COSINE FUNCTIONS
}

\author{
SEÁN M. STEWART
}

\begin{abstract}
A class of four improper integrals containing the square of the tail of the sine and cosine functions in their integrand are found using Fourier transform methods. Relations between the four improper integrals considered are given and an open problem concerning the general form of certain improper integrals of this type is raised.
\end{abstract}

Mathematics subject classification (2010): Primary: 40C10; Secondary: 42A38.

Keywords and phrases: Improper integral, Fourier transform, Laplace transform, binomial identity.

\section{REFERENCES}

[1] W. ApPel, Mathematics for Physics and Physicists, Princeton University Press, Princeton, 2007.

[2] J. EdWARDS, A Treatise on the Integral Calculus with Applications, Examples and Problems, Macmillan and Co., London, 1922.

[3] D. W. Kammler, A First Course in Fourier Analysis, Cambridge University Press, Cambridge, 2007.

[4] C. Lindman, De integralibus quibusdam definitis, Arch. Math. Phys., 16, (1851), 94-103.

[5] S. M. Stewart, Problem 2092, Math. Mag., 93, 2 (2020), 150.

[6] B. VAN DER POL AND J. Wichers, Vraagstuk CIL, Wiskundige Opgaven met de Oplossingen, 17, (1942), 364-365.

[7] J. Wolstenholme, Mathematical Problems on the First and Second Divisions of the Schedule Subjects for the Cambridge Mathematical Tripos Examination, Second Edition, Macmillan and Co., London, 1878. 